\title{
História e Cultura indígena: estudo e pesquisa durante as aulas remotas no ensino superior
} Indigenous History and Culture: study and research during remote classes in higher education

Historia y cultura indigena: estudio e investigación durante las clases remotas en la educación superior

\section{SUELI DO NASCIMENTO ${ }^{1}$, ALONSO BEZERRA DE CARVALHO ${ }^{2}$}

${ }^{1}$ Faculdade de Filosofia e Ciências da Universidade Estadual Paulista - Unesp - Marília/SP

${ }^{2}$ Faculdade de Filosofia e Ciências da Universidade Estadual Paulista - Unesp - Marília/SP

\begin{abstract}
RESUMO: Expõe-se aqui o resultado das aulas remotas transmitidas durante a pandemia Covid-19, abordando a temática indígena, com base na Lei $n^{\circ} 11.645 / 08$, relativa ao ensino superior. Objetivo foi o de fomentar a transição da consciência ingênua freireana e a prévia rüseniana, a partir do saber histórico de 26 acadêmicos do curso superior em Engenharia da Computação, no período de agosto a novembro de 2020, no UniS ALESLANO (Centro Universitário Católico Salesiano Auxilium), Araçatuba/SP. Abordarse-á aqui o processo da temática relacionada aos povos indigenas, focando a desmitificação, as lacunas e, sobretudo, a desconstrução de conceitos e preconceitos apresentados nas dissertaçöes dos alunos sobre tais povos. A se destacar a importância da partilha no Grupo de Estudo e Pesquisa em Educação, Ética e Sociedade (Gepees), que possibilitou esta ininterrupta construção-desconstrução-construção em nossa ação, enquanto pesquisadores, no âmbito da educação e das estratégias utilizadas, que contribuíram para o processo da formação da consciência histórica.
\end{abstract}

CONSCIÊNCIA HISTÓRICA. ENSINO SUPERIOR . HISTÓRIA E CULTURA INDÍGENA.

\begin{abstract}
The results of remote classes transmitted during the Covid-19 pandemic are exposed here, addressing the indigenous theme, based on Law No.11,645 / 08, related to higher education. Objective was to foster the transition from naive Freirean consciousness and the previous Rüsenian, based on the historical knowledge of 26 undergraduate students in Computer Engineering, from August to November 2020, at UniS ALESLANO (Centro Universitário Católico Salesiano Auxilium), Araşatuba/SP. The process of the theme related to indigenous peoples will be approached here, focusing on demystification, gaps and, above all, the deconstruction of concepts and prejudices presented in students' dissertations about such peoples. To highlight the importance of sharing in the Study and Research Group on Education, Ethics and Society (Gepees), which enabled this uninterrupted construction-deconstruction-construction in our action, as researchers, in the scope of education and the strategies used, which contributed for the process of forming historical consciousness.
\end{abstract}

HIGHER EDUCATION. HISTORICAL AWARENESS. INDIGENOUS HISTORY AND CULTURE.

Os autores cedem à Revista Internacional Educon os direitos de primeira publicação do presente artigo. Aplicam-se os termos de uma licença Creative Commons Atribuição 4.0 Internacional (CC BY 4.0), que permite o uso irrestrito, a distribuição e a reprodução em qualquer meio desde que a publicação original seja corretamente citada. 
RESUMEN: Aqui se exponen los resultados de las clases remotas transmitidas durante la pandemia Covid-19, abordando el tema indígena, con base en la Ley $N^{\circ} 11.645$ / 08, relacionada con la educación superior. El objetivo fue fomentar la transición de la conciencia freireana ingenua y la rüseniana anterior, a partir del conocimiento bistórico de 26 estudiantes de grado en Ingeniería Informática, de agosto a noviembre de 2020, en UniS ALESLANO (Centro Universitário Católico Salesiano Auxilium), Araçatuba/SP. Aqui se abordará el proceso de la temática relacionada con los pueblos indigenas, enfocándose en la desmitificación, las brechas y, sobre todo, la deconstrucción de conceptos y prejuicios presentados en las disertaciones de los estudiantes sobre dichos pueblos. Destacar la importancia de compartir en el Grupo de Estudio e Investigación en Educación, Ética y Sociedad (Gepees), que posibilitó esta construccióndeconstrucción-construcción ininterrumpida en nuestra acción, como investigadores, en el ámbito de la educación y las estrategias empleadas, que contribuyeron para el proceso de formación de la conciencia bistórica.

\section{CONCIENCIA HISTÓRICA. EDUCACIÓN SUPERIOR. HISTORIA Y CULTURA INDÍGENA.}

\section{Introdução}

Adentrar a sala de aula virtual é organicamente tornar-se parte das novas Tecnologias da Informação e Comunicação (TIC), até porque, atualmente, a maioria de nossos alunos é fluente na linguagem digital, pois os jogos de computador, internet e smartphones efetivamente compõem o seu cotidiano, embora o público desta pesquisa seja o do curso de Engenharia da Computação ${ }^{1}$ e o que aqui se estabelece é uma relação entre software e hardware, tanto em termos de programação, quanto entre sistemas 'embarcados', além da mera utilidade cotidiana.

Este artigo é um recorte do resultado alcançado nas aulas, remotas em razão da pandemia de Covid-192. A abordagem da temática indígena é feita em base à Lei no 11.645/08.

Neste caso, o ensino remoto não pode ser confundido com o EaD - Ensino a Distância pois, nas aulas remotas, nossa proposta, feita por meio da investigação, acabou por transformar os alunos em sujeitos ativos nesse processo de desmitificação, de preenchimento de lacunas e, sobretudo, de desconstrução de conceitos e preconceitos, que aparecerão em algumas dissertações sobre os povos indígenas.

Acreditamos que a aprendizagem, por conta deste sistema remoto, exija que se confie nos sujeitos, para instigar a percepção intelectual de compreender conceitos, assim como a exercitar metodologias como nova alternativa de se abordar a temática e uma nova metodologia no desenvolvimento de estudos. O desafio não é somente conectar-se numa linguagem digital com o alunado, mas, principalmente, um despertar reflexivo - que tem por objetivo fomentar a transição da consciência ingênua freireana e prévia rüseniana, a partir do saber histórico dos acadêmicos citados face à temática relacionada aos povos indígenas e através de novos meios e modos.

Neste contexto, serão mencionados alguns trechos das dissertações, pela importância do trabalho, que teve a participação de 26 acadêmicos do curso superior em Engenharia da Computação, no período de agosto a novembro de 2020 , no já referido centro salesiano.

No início do processo, propuseram-se aos acadêmicos duas questões: a) "Como observam a participação dos indígenas?"; b) Significado das palavras "índio na história do Brasil". As indagações-

\footnotetext{
1 O curso forma profissionais capacitados para atuar em projetos, desenvolvimento, implantação e otimização de sistemas computacionais, integrando as mais novas plataformas hardware e software.

2 A COVID-19 é uma doença causada pelo coronavírus, denominado SARS-CoV-2.
} 
submetidas aos participantes foram feitas respeitada a autorização do Certificado de Apresentação para Apreciação Ética (Caae) 99345118.4.0000.8030, parecer $^{3} \mathrm{n}^{\circ}$ 3.057.878.

A pesquisa, de natureza qualitativa, foi concluída em 30 de novembro de 2020, no curso de Engenharia da Computação, na disciplina de História e Cultura Afro-Brasileira e Indígena.

Nas aulas, na aplicação do conteúdo da disciplina, foi adotado um processo que utiliza estratégias e materiais relativas a um recorte histórico-literário do século XVIII ao XXI, incluindo leitura, análise e correlação entre filme e literatura do período, seguidas de propostas dissertativas ${ }^{4}$. Cabe especificar que nesta pesquisa se recorreu ao pensamento rüseniano e freireano, estabelecendo com os autores o que na linguagem corrente em nosso meio passou a se chamar de "diálogo teórico". Ao Recorrer ao passado e ao analisar as fontes propostas, em base ao pensamento destes autores, buscávamos interpretar o momento presente, no intuito de agir em prol de um "processo mental de construção de sentido sobre a experiência do tempo" (Rüsen, 2010a, p. 43).

Este embasamento foi o que nos levou a propor ao ensino superior uma aprendizagem significativa que envolvia autonomia e diálogo para, substancialmente, transpor desafios, instigar novas lutas, seja em oposição à técnica neutra e à opressão ideológica, seja pela possibilidade de gerar receitas positivistas e funcionalistas de ensino. De acordo com Freire, pode-se perceber que "[...] somente uma escola centrada democraticamente no seu educando e na sua comunidade local, vivendo as suas circunstâncias, integrada com seus problemas, levará os seus estudantes a uma nova postura diante dos problemas de contexto (2003, p. 85).

Dialeticamente, na tarefa permanente de transformação, na complexidade desse trabalho dito humanizador, efetiva-se a desmistificação dos estereótipos citados por Hall (2015), mas numa realidade mais crítica para desvelar os mitos que enganam e ajudam "a manter a realidade da estrutura dominante" (Freire, 2016, p. 60). Tais concepções, discutidas em sala de aula, desafiam embaraçosamente a educação. Como ajudará ela o homem a constituir sua vida, a se tornar sujeito? Em que condições vive ele? Faz ele ideia do seu momento e do seu contexto?

Tais inquietações, necessárias, nos remetem a esse trilhar de estudo e pesquisa; por isso, consideramos, paralelamente, relevante contemplar a partilha no Grupo de Estudo e Pesquisa em Educação, Ética e Sociedade (Gepees), que possibilitou esta ininterrupta construção-desconstruçãoconstrução em nossa ação enquanto pesquisadores no âmbito da educação. As estratégias utilizadas contribuíram para o processo da formação da consciência histórica.

Neste último caso, as reuniões com o grupo, também remotas, instigaram a trazer novas discussões que contribuíram para a professora-pesquisadora em sala de aula virtual. Ponto de relevância no que concerne à sua formação docente, especialmente à formação continuada que proporciona novas inquietações de estudo e pesquisa e, consequentemente, se refletem no exercício da profissão. Apresentaremos, também, relatos de quatro integrantes desse grupo de estudo e pesquisa, que gentilmente responderam a duas questões significativas, que mencionaremos no decorrer deste artigo.

$\mathrm{Na}$ discussão, propusemo-nos descrever a importância de uma estratégia para fomentar, entre acadêmicos, o processo de formação da consciência histórica, juntamente com o de se fazer parte desse grupo -, para caminharmos pensando o quanto esse contínuo processo de formação é essencial e relevante, mas vinculado à sala de aula. Nosso intuito não é receitar caminhos, mas promover novos olhares e despertar novas estratégias em meio a tantos dissabores que enfrentamos na atual conjuntura. Este artigo é um “esperançar” por dias de encontro de contínua formação em coletividade.

\footnotetext{
3 Parecer consubstanciado na aprovação emitida de acordo com a Plataforma Brasil.

4 As propostas dissertativas ocorreram após a apresentação de cada linguagem cultural, como condição de o alunado expor seus posicionamentos sobre a temática.
} 


\section{Processo utilizado durante as aulas remotas e a temática indígena}

A perspectiva educacional em que se baseiam as aulas é um caminho de valorização e respeito do outro, um estímulo aos sujeitos a descobrir a possibilidade de transformação, numa ação-reflexão-ação, de um processo aliado à história e à cultura, contextualizado com a realidade, com o entorno, com a vida a que historicamente se pertence, para dialogar, num movimento dialético, com "a reflexão crítica sobre a ação anterior e a subsequente ação no processo [...]" (Freire, 1981b, p. 88), de forma conjunta, educador e alunado. Este processo metodológico foi desenvolvido durante o segundo semestre de 2020, utilizando a seguinte estratégia que envolveu conteúdo e literatura.

Quanto a conteúdo, visão histórica e dialética dos processos sociais em curso (raça, racismo) e o lugar do indígena, analisado, na filmografia: Terra Vermelha, direção de Marco Bechis. Itália/Brasil: Paris Filmes, 2008, com duração de 108 minutos; o documentário Indigenas Digitais - novas alternativas para falar ${ }^{5}$, que mostra a relação dos indígenas com as tecnologias de comunicação, de direção de Sebastián Gerlic, 2010, com duração de 26 minutos.

Quanto à literatura, foi predeterminado um recorte histórico-literário do século XVIII ao XXI, feito de produções essencialmente brasileiras e de fácil acesso virtual, julgadas pertinentes à temática da proposta. Para tal efeito, foram escolhidos os seguintes livros: Iracema (1865), de José de Alencar; Macunaíma (1928), de Mário de Andrade; Maíra (1976), de Darcy Ribeiro; A Majestade do Xingu (1997), de Moacyr Scliar.

Os livros foram enviados a cada estudante em PDF, embora também estivessem disponíveis em formato físico - na coleção pessoal da professora. O objetivo desta atividade foi destacar trechos, personagens e o contexto em que cada um se inseria, para observar e discutir a representação e a participação do indígena no desenrolar do enredo de cada livro.

Estas linguagens, que nós - professora e acadêmicos - consideramos culturais (livros de literatura e filmes), propiciaram a discussão sobre a história do indígena no Brasil.

Neste artigo, descreveremos a prática relacionada à literatura. Cada trecho apresentado é o resultado das dissertações que cada acadêmico escreveu durante as aulas, acrescido das discussões e conteúdos construídos por meio de diálogo e pesquisa.

A linguagem cultural colaborou nesse ato de (des)construir preconceitos e instigar o pensamento, segundo o qual se abre "uma perspectiva de futuro mediante a práxis do presente, a partir da experiência do passado. Nessa perspectiva, são (podem ser) inseridas as determinações finalísticas do agir humano" (Rüsen, 2015, p. 147).

Foi nesse agir humano que se buscou - como sugere Freire (2003, p. 82) - passar da consciência intransitiva à transitiva ingênua, para que acadêmicos conquistassem o poder do diálogo - para, assim, romper com a consciência ingênua e dela passar para a consciência crítica, democraticamente estabelecendo conexões em suas narrativas com o presente, o passado e o futuro na historicidade, enterrando o campo minado do colonialismo, e seguindo, com autonomia, o seu próprio palmilhar. Rüsen (2010b, p. 72) recomenda compreender o "pluralismo do potencial interpretativo da consciência histórica”, possibilitando "espaço não arbitrário de interpretação do pensamento histórico. Tal pluralismo estabeleceria uma relação equilibrada entre memória e experiência". Para tanto, acredita-se que a conscientização "não pode existir fora da práxis, ou melhor, sem o ato ação-reflexão. Esta unidade dialética constitui, de maneira permanente, o modo de ser ou transformar o mundo que caracteriza o homem" (Freire, 1980, p. 26).

5 Link do documentário: https://www.youtube.com/watch?v=T2I7ovB6E7k. 


\subsection{Temática indígena no recorte histórico-literário do século XVIII ao XXI e dissertações}

A escolha dos trechos a serem apresentados foi predeterminada na quantidade de seis exemplificações para discussão, devido à extensão do trabalho, mas num processo em que a:

[...] natureza formadora da docência, que não poderia reduzir-se a um puro processo técnico e mecânico de transferir conhecimentos, enfatizar a exigência ético-democrática do respeito ao pensamento, aos gostos, aos receios, aos desejos, à curiosidade dos educandos. Respeito, contudo, que não pode eximir o educador, enquanto autoridade, de exercer o direito de ter o dever de estabelecer limites, de propor tarefas, de cobrar a execução das mesmas. Limites, sem os quais, as liberdades correm o risco de perder-se em licenciosidade, da mesma forma como, sem limites, a autoridade se extravia e vira autoritarismo (Freire, 1997, p. 39).

Seguem-se exposições de alunos 6 , identificados por letras, para proteção de sua identidade. Escreve o aluno A:

[...] os indígenas são os povos originais das terras brasileiras, pois já estavam aqui quando as embarcações portuguesas chegaram no Brasil e iniciou-se a colonização. Desde aquele tempo os indígenas são maltratados [...] sofrendo com invasões territoriais, discriminação e supressão cultural até os dias atuais. Analisando livros, que dizem respeito à cultura indígena, pode-se notar que tal avanço do homem branco sobre os territórios descobertos na época da colonização, como citado em um diálogo de Iracema por Alencar (1865) onde diz que: "Venho de bem longe, filha das florestas. Venho das terras que teus irmãos já possuíram, e hoje têm os meus". Tais fatos aconteceram de forma desenfreada durante o decorrer da história brasileira, deixando os indígenas isolados em poucas terras ou até mesmo sem elas, devido à exploração e abuso de território. Além da tomada territorial, podemos notar um grande impacto na cultura dos índios, onde suas crenças e costumes foram observados e estudados pelo homem branco de forma superficial, ou seja, o conhecimento que temos sobre os índios atualmente são preconcepções criadas pelos não indígenas. Isso se reflete nos livros que se referem aos índios, que consequentemente sofrem com a europeização da história, sempre muito romantizado, fazendo parecer que algumas atrocidades nos livros da época, soe como algo normal. Além da imposição de crenças, como vemos em um trecho de Macunaíma, por Andrade (1928) onde o homem branco "andava pregando o evangelho de Jesus pra indiada brasileira". Mas desde muito tempo, a única coisa que os indígenas querem é que suas terras sejam mantidas, como vemos em Maíra, por Ribeiro (1976) onde é dito: "Sabemos que o que ele e todos os brancos nos podem dar de melhor é não se meterem na nossa vida. É nos deixar em paz." Enquanto o homem branco busca por materiais, bens, propriedades e riquezas, os indígenas só precisam da terra, pois é com base nela que toda uma tribo tira seu sustento. Por fim, analisando o texto de Scliar (1997) no livro A Majestade Do Xingu, que diz: "O conde Alexei era o dono de tudo naquela região [...] Possuía grandes extensões de terra, mas ou era um nobre arruinado - conde que se preza não manda consertar sapatos, joga fora - ou então era um homem muito econômico -, pode ser notado que mesmo o branco tendo tanto, "não consegue produzir o suficiente para si", enquanto com tão pouco o índio produz pra tribo toda.

Segue-se o depoimento do aluno B:

6 Cabe especificar que se apresentam neste artigo, fragmentos das dissertações que citam os seguintes livros: Iracema (1865), de José de Alencar; Macunaíma (1928), de Mário de Andrade; Maíra (1976), Darcy Ribeiro; A Majestade do Xingu (1997), de Moacyr Scliar. 
[...] protagonista da história se encontra frente a um guerreiro que também poderia ser um mau espirito, trazendo o tom das origens indígenas, que atribuem entidades à natureza até hoje diante dela e todo a contemplá-la está um guerreiro estranho, se é guerreiro e não algum mau espírito da floresta, o que fica explicito no trecho "Diante dela e todo a contemplá-la está um guerreiro estranho, se é guerreiro e não algum mau espírito da floresta" (ALENCAR, 1865, p. 5). No segundo texto temos o dia a dia de uma criança nagô, fazendo alusão ao povo escravizado e vendido que ainda mantem ligação com suas raízes religiosas de origem e ainda podemos ver logo a frente do trecho como a cultura indígena possuía suas próprias crenças e regras em ditados, ao trazer que as características adultas já apareciam logo na infância, Mario de Andrade (1928) escreveu: "Nas conversas das mulheres no pino do dia o assunto eram sempre as peraltagens do herói. As mulheres se riam muito simpatizadas, falando que "espinho que pinica, de pequeno já traz ponta", e numa pagelança Rei Nagô fez um discurso e avisou que o herói era inteligente". (p. 2). Mayra traz a questão do conflito, do abandono de suas origens e de como a sociedade suprime a cultura indígena, tendo esta como algo ultrapassado e não levando em consideração que os povos indígenas são providos de subjetividade e essas ações de "pacificação" por parte das instituições, que viam a cultura do índio como algo hostil ou que pudesse ser melhorada, no trecho onde Darcy escreve as ações dos pacificadores e seus meios de pacificação onde o orientador científico foi quem lhes demonstrou que a técnica básica de pacificação consiste em implantar no coração da tribo hostil, como uma provocação, um núcleo para atrair a sua hostilidade (p. 220, 1976). No livro A Majestade do Xingu de Moacir Scliar de 1997 podemos ver um paralelo da cultura indígena com a do protagonista, que sente que suas origens também serão futuramente esquecidas. Importante ressaltar que o mesmo ainda tem as embarcações portuguesas como referencias de beleza, luxo e ao mesmo tempo tristeza, não muito diferente do que a história conta a respeito da chegada dos portugueses ao Brasil, onde trouxeram suas luxuosidades e os índios se contentarem com o massacre de sua gente, diz o protagonista "Como os idiomas dos índios, logo estará esquecida. Não vem ao caso, muita coisa logo estará esquecida" (p. 11). A história da literatura brasileira retrata a cultura indígena, mas ainda sim a trata através de um viés colonizado, sempre com um olhar "altivo" para suas conquistas e modos de viver, seja trazendo modos de pacificação como fora citado acima ou dizendo que logo estará esquecida, colocando-a lado a lado com outros povos emigrantes. Cultura Indígena deve ser escrita por Índios, que não a utilizam para ganhar meios de promover um período que consiste em ressaltar modos de vida totalmente contrários aos valores indígenas.

\section{Depoimento do aluno C:}

O escrever de uma história, como toda arte, se tem origem em emoções humanas geradas pela percepção de mundo de quem a escreve, o autor geralmente busca passar por meio de cenários e personagens (fictícios ou não) impressões que o mesmo tem sobre aspectos e sentimentos reais. Porém, quando um conto é escrito em forma de relato com personagens muito parecidos e atuais, com o contexto em que o mesmo foi escrito, quando não se autoafirma "baseado em fatos reais", uma dúvida costuma pairar sobre as indagações do leitor, "até que ponto este relato é verídico?". Em histórias com base na cultura indígena tal sentimento é muito presente, tendo em vista que dependendo do tempo em que a narrativa foi escrita, podemos ver diversas mudanças na forma em que o povo indígena foi representado em obras literárias. Como por exemplo, em Iracema vemos um estilo de escrita mais romântico e de certa forma até mesmo "místico" nos momentos em que Alencar por repetidas vezes dita a personagem como "[...] virgem dos lábios de mel [...]" (Alencar, 1865, p. 5) ou em outro momento onde a mesma " [...] fez ao estrangeiro um gesto de espera e silêncio, e depois desapareceu no mais sombrio do bosque. O Sol ainda pairava suspenso no viso da serrania; e já noite profunda enchia aquela solidão. Quando a virgem tornou, trazia numa folha gotas de verde e estranho licor vazado da igaçaba, que ela tirara do seio da terra. Apresentou ao guerreiro a taça agreste. - Bebe!" (Alencar, 1865 , p. 14) para buscar um pouco de licor para o personagem referido por eles como "estrangeiro". Vindo como antítese, temos 
em Macunaíma, Mário de Andrade descreve o protagonista logo no início como garoto que só “[...] fez coisas de sarapantar [...]" (Andrade, 1928 p. 2 ), ele disserta sobre a vida do personagem em um tipo de escrita muito semelhante à um "grande poema" que apesar de bem escrito e com termos de época, não pinta o garoto como um "grande herói", na verdade ele passa mais um ar de "anti-herói”, deixando a índole do personagem bem questionável, e até mesmo de certa forma, mais parecida com um relato do que com uma "lenda", podemos também notar uma evidente busca da identidade um povo, com uma escrita nacionalista também. Tempos depois, em Maíra de Darcy Ribeiro temos discussões sobre a identidade, sobre o que é "ser índio", temos trechos em que a identidade do personagem Isaías é posta a prova por outra personagem da seguinte forma: "Você não é mais índio coisa nenhuma. É um civilizado que nem eu." (Ribeiro, 1976, p. 165-) e o mesmo responde à esta afirmação discordando do ponto da personagem e ressaltando que “[...] coisas todas que aprendi formam uma espécie de roupa do meu espírito. É uma camada superficial, solta, frouxa. No fundo, como um caroço, está meu sentimento do mundo de mairum. Esta é a minha raiz mais funda. É a semente. É aquilo que, fazendo de mim um homem, me faz, ao mesmo tempo, membro de minha tribo, gente mairum" (Ribeiro, 1976, p. 165), deixando claro que o "ser indígena" não é apenas "parecer indígena", tem relação com a essência do ser. Temos também em A Majestade do Xingu, Moacyr Scliar descreve "[...] uma aldeia bem pequena, a nossa, e de gente muito pobre" (Scliar, 1997, p. 11), dando uma visão de um lado mais "miserável" de ser índio. Apesar de cada história ser escrita por autores diversos em contextos históricos diferentes, podemos assim, estudando o contexto em que a história foi escrita, o gênero literário e o próprio autor por si, traçar um paralelo com a realidade, com relatos ditados pelos próprios descendentes, pelos próprios indígenas e assim é possível aprender e nos aproximar mais e mais sobre a cultura de nossa origem brasileira.).

\section{Depoimento do aluno D:}

[...] o dia 28 de outubro foi marcado no supremo tribunal federal o julgamento do marco temporal. Neste julgamento os ministros iriam decidir se os índios teriam direito originário sobre suas terras, para eles possuir esse direito o espaço devia estar sendo ocupado quando fora dia 05 de outubro de 1988. A questão é que as terras são dos índios desde muito tempo atrás, no trecho descrito por Alencar (1865) mostra que bem antes desta data já havia índios no país "O cristão adormeceu ouvindo suspirar, entre os murmúrios da floresta, o canto mavioso da virgem indiana.", o livro foi publicado 23 anos antes da data proposta pelo marco, e já demonstrava a presença indígena, este marco só afirma toda a opressão que os mesmos sofrem para largar suas raízes e se "modernizar" deixando de lado toda uma cultura. Essa autocracia não é uma novidade assim como Andrade (1928) deixa claro em seus livros Macunaíma "Quando o herói saiu do banho estava branco louro e de olhos azuizinhos, água lavara o pretume dele. E ninguém não seria capaz mais de indicar nele um filho da tribo retinta dos Tapanhumas" e a majestade do Xingu "Como os idiomas dos índios, logo estará esquecida. Não vem ao caso, muita coisa logo estará esquecida" essa tentativa de transformar o índio em branco já é bem mais antigo que qualquer marco, e basta remover suas terras para remover suas histórias. Esse marco temporal só afirma a narrativa onde o índio é tratado como escoria da sociedade, porém os índios são bem mais donos das terras onde eles pisam do que qualquer homem branco pode ser, nessas terras estão todo uma cultura passada de gerações por gerações que não pode ser retirado assim de uma hora para outra, pois apesar de toda essa perseguição que eles sofrem, seus ensinamentos e crenças são atemporais, Ribeiro (1976) já reforçava em Maira "Mas os índios contam esta história lá do jeito deles. Dizem que foram eles que amansaram meu pai, com muito trabalho. Através dele conheceram outros brancos que já não chegavam atacando, atirando, matando gente" o povo indígena apenas quer ser respeitado.

Depoimento do aluno E: 
[...] a cultura e a literatura brasileira quase sempre os deixaram de lado retratando de forma muito equivocada a forma que um indígena vive e reage em algumas situações básicas do cotidiano, até mesmo a forma que os colonizadores interagiam com os índios em muitos casos acaba sendo muito fantasiosa. Alencar (2018, p. 28) diz em seu conto "O guerreiro branco é teu esposo: ele te pertence." Neste trecho é romantizado o sentimento dos colonizadores para com os índios, a realidade é outra a escravidão era totalmente legal e natural na época da primeira versão deste livro. Nesta outra obra Ribeiro (1976, p. 293) diz "a estratégia da FUNAI é congelar os índios em seus costumes.... São doutrinas, dizem eles, mas que doutrinas?”, tratando as crenças indígenas como se fossem algo desnecessário e facilmente descartável, mas não mostra que para os índios esse fato também serviria para as crenças dos colonizadores. Andrade em seu livro Macunaíma $(1928,50)$ tem um capítulo no qual o protagonista indígena participa de um ritual [...], distorcendo completamente a cultura religiosa indígena [...] ignorando fatos históricos que marcaram a época.

\section{Depoimento do aluno F:}

Desde os tempos antigos do imperialismo, o homem branco impõe um sentimento de superioridade. Com o surgimento do capitalismo a necessidade das pessoas de se inserirem no cenário globalizado só aumenta. Nesse contexto, ideologias similares as usadas no período imperial, ainda existem de modo a excluir e marginalizar aqueles que não se enquadram nesse novo modelo de sociedade. No Brasil estes casos ocorrem com as culturas e povos indígenas que ainda sofrem com preconceito e discriminação. Retratado em Iracema por Alencar (1865, p. 2): "Diante dela e todo a contemplá-la está um guerreiro estranho, se é guerreiro e não algum mau espírito da floresta. [...] Foi rápido, como o olhar, o gesto de Iracema. A flecha embebida no arco partiu" . Neste trecho é retratado Iracema provavelmente tendo seu primeiro contato com um homem branco que a observava ao longe, sua reação instintiva de defesa mostra que a mesma não possuía familiaridade com aquele ser até então estranho para ela. Já no trecho de Macunaíma de Andrade (1928, p. 63) "Cidade é belíssima, e grato o seu convívio. Toda cortada de ruas habilmente estreitas e tomadas por estátuas e lampiões graciosíssimos e de rara escultura; tudo diminuindo com astúcia o espaço de forma tal, que nessas artérias não cabe a população", podemos observar as primeiras impressões de um indígena ao visitar uma zona urbana densa como a cidade de São Paulo, ficando impressionado ao se deparar com prédios e ruas, [...] foi uma choque de cultura e informação tremendo. Em Maíra de Ribeiro (1976, p. 19): "Belga ou holandês pode catequizar índio. Espanhol e italiano e até norte-americano pode pregar na Itália, na França, no Brasil, onde quiser. Mas eu, índio mairum, posso ser sacerdote deles? Nunca!", o personagem relata sobre os povos belgas e holandês poderem impor suas culturas e crenças aos índios, outros povos poderem se tornar sacerdotes, e indaga se ele, índio, mairum poderia ser sacerdote. Isso devido os acontecimentos de colonização durante as grandes navegações e a imposição das culturas dos povos mais avançados sobre os mais fracos, apesar de ter ocorrido há muito tempo, isso ainda reflete e ocorre nos tempos atuais.

Para A majestade do Xingu, de Scliar (1997, p. 11): "Morávamos numa pequena aldeia, num shtetl, como se dizia em iídiche. Iídiche, doutor: ninguém mais fala essa língua. Como os idiomas dos índios, logo estará esquecida". Neste trecho podemos observar a comparação feita pelo personagem, que é originário de uma pequena aldeia na Rússia, e relata que sua língua natal já não existe mais, como as dos índios no Brasil, isso por conta da intervenção e imposição de outras línguas, culturas e costumes aos povos mais frágeis. Assim, como os exemplos citados, é inegável que a sociedade atual, capitalista, se sobreponha as culturas que não se adequem a ela. Para que estas culturas e conhecimentos não se percam, torna-se necessário um maior investimento na educação nas áreas de humanas. 


\subsubsection{Discussões entre professora e acadêmicos - o diálogo como esperançar}

Cabe relatar, neste contexto, o quanto as discussões sobre a temática indígena fizeram aflorou outros questionamentos pertinentes à historicidade, como, por exemplo: a revolta, a revolução, a guerra, o golpe e o fascismo. Dialogar sobre esses temas na atual conjuntura é indispensável à multiplicação de conhecimentos, no intuito não somente de formação, mas no de buscar por justiça e 'vida integral' (total realização do ser humano), que Dussel (2012, p. 632) explica estar na "dimensão físico-biológica, histórico-cultural, ética, estética e até mesmo místico-espiritual”. Daí a importância sobre:

[...] o outro que habita em nós - medos, faltas e falhas. Todavia, se o reconhecimento dessas dimensões não ocorre ou elas não são levadas em consideração, a tendência é acarretar violências incontroláveis e conflitos contra os outros, contra a polis, na verdade, contra si mesmo (Carvalho, 2016, p. 204-205).

Nesse processo, discutiu-se sobre violências incontroláveis e conflitos contra os outros, como alerta Carvalho (2016), em assuntos como a invasão dos territórios indígenas pelo governo do estado e pelas colonizadoras, momento em que se hão de investigar os possíveis ataques (violências e conflitos) durante a construção da ferrovia, a criação do SPI e a organização de expedições de pacificação. Isto para se refletir sobre a complexidade do pensamento decolonial, no que cerne à "colonialidade", no fundamento do novo padrão de poder e no movimento que fundou um modo de existência social chamado "modernidade", num momento em que se acredita deva intervir o papel da ética enquanto defensora da vida integral, ou, mais especificamente, no ponto em que o 'Outro' - cansado de ser excluído -, deva ser incentivado a buscar por sua libertação. Para que isso ocorra, porém, será necessária a tomada de consciência freireana, que requer outro sistema ético e outra história de vida. Afinal, não podemos simplesmente endossar a imagem desses povos pelo que deles fala a história oficial. Não é admissível que tenham aceito passivamente e passivamente continuem encurralados em "territórios oficiais".

Cabe também refletir sobre o que Bauman (1995, p. 21) afirma ao se referir à ética, quando diz ser preciso ir "[...] além da descrição do que as pessoas fazem; mais do que uma descrição do que creem dever fazer a fim de serem decentes, justas, boas - ou, mais geralmente, a fim de agirem como deve ser".

Neste presumível agir, pretendeu-se romper com o sistema ético vigente - imposto pelo eurocentrismo, que não respeitou a cultura e a ética dos povos indígenas. Buscou-se, numa práxis de libertação e de transformação da ética vigente, a defesa do direito dos excluídos pertencentes às etnias para, possivelmente, contribuir na multiplicação de outras pesquisas e insurgências numa ética pela vida.

Em comunhão com o que se expôs, citamos, a propósito, o que escreve Quijano (2006, p. 49) sobre a constituição da Europa Ocidental como centro mundial de controle de poder, ou seja, a "colonialidade do poder que possivelmente produziu o des/encontro na experiência histórica das etnias caingangues e terenas com possíveis, ou não, consequências de dominação, de apropriação e de racismo moderno/colonial".

Retornando a Dussel (1993, p. 58-59), este escreveu que "por isso entendemos o domínio que os europeus exerceram sobre o 'imaginário' do nativo, conquistado antes pela violência das armas. É um processo de racionalização próprio da Modernidade".

Assim, Quijano (2005, p. 127) afirma que "no momento em que os ibéricos conquistaram, nomearam e colonizaram a América (cuja região norte, ou América do Norte, colonizarão os britânicos um século mais tarde), encontraram um grande número de diferentes povos". Povos que possuíam sua própria história, linguagem, cultura, memória e identidade. Dentre eles, alguns "mais desenvolvidos e sofisticados: astecas, maias, chimus, aimarás, incas, chibchas, etc. Trezentos anos mais tarde, todos eles reduziam-se a uma única identidade: índios" (Quijano, 2005, p. 127). 
Será possível, através desta ressignificação de identidades, despertar a consciência dos homens, posto que Freire (1981b) explica que tal ressignificação não acontece "isolada do mundo, senão na práxis dos homens dentro da história que, implicando na relação consciência-mundo, envolve a consciência crítica desta relação" (Freire, 1981b, p. 79-80).

\section{Grupo de Estudo e Pesquisa em Educação, Ética e Sociedade (Gepees) e os encontros remotos}

O Gepees, que existe desde 2008, e está devidamente cadastrado no CNPq, nasceu de um objetivo mais específico: o de estudar o pensamento de sociólogos e filósofos, o que explica a temática Educação, Ética e Sociedade. A criação do grupo foi iniciativa de Alonso Bezerra de Carvalho, que era e ainda é o líder. Carlos da Fonseca Brandão fazia parte do grupo como vice-líder, atualmente substituído por Genivaldo de Souza Santos. Posteriormente, agregaram-se temas afins aos da proposta inicial, como o da Psicologia e o de Ética. Esta acabou por se sobressair em razão da guinada nos fundamentos da Educação, que propôs 'ética e relações humanas' na sala de aula, traduzidas por amizade e paixões humanas. Procuramos embasamento em Aristóteles, cuja filosofia se prestou a diversos projetos de pesquisa de orientandos (mestrandos e doutorandos). Nessa sequência de estudos, em continuidade a novas abordagens, nos chegamos, mais recentemente, ao pensamento latino-americano, numa aproximação entre Antropologia e Sociologia, articuladas com a Filosofia. A oportunidade deu lugar a uma discussão subliminar sobre decolonialidade, interculturalidade, pois levou a estudar Rodolfo Kusch.

Este histórico, que ao mesmo tempo expõe um trajeto, explica o objetivo do grupo de investigar e compreender a presença da ética na sociedade contemporânea, e suas interfaces com a educação, a partir das ideias filosóficas e sociológicas de clássicos das ciências humanas. Recentemente, membros do grupo organizaram uma coletânea a que denominaram "Pensamento Latino-Americano e Educação: por uma ética situada", na qual se apresentam textos dedicados ao pensamento latino-americano e à educação, estabelecendo-se como fio condutor uma "ética situada".7

\subsection{Entrevistas - integrantes do Grupo de Estudo e Pesquisa em Educação, Ética e Sociedade (Gepees)}

Para repassar algumas das grandes linhas de pensamento do grupo, seja em termos de "grupo de estudo" quanto de "formação continuada", submetemos duas questões a alguns membros que espontaneamente se dispuseram, assim colocadas:

1 - Qual a relevância do 'Grupo de Estudo e Pesquisa' em sua formação continuada?

2 - Em termos de composição do 'Grupo de Estudo e Pesquisa', o que ele pode representar para você e sua vida?

O membro A respondeu aos dois itens da questão:

1 - Considero o Grupo de Estudo e Pesquisa muito relevante. No grupo, é possível refletir além do que é pensado ou dado em disciplina. Considero que o grupo de estudos seja um aprimoramento de ordem

\footnotetext{
7 Link da coletânea: https://ebooks.marilia.unesp.br/index.php/lab_editorial/catalog/book/170>.

8 Pertence à Faculdade de Filosofia e Ciências da Universidade Estadual Paulista (Unesp), em Marília/SP.
} 
acadêmica, e também pessoal, pois, ao tratar de trocas e encontros de conhecimento, envolve também trocas simbólicas de uma vida coletiva.

2 - O grupo representa, para mim, um progresso pessoal e acadêmico, no qual trago questões que vão além da ordem de 'utilitarismo' para a tese, e sim de ordem de curiosidade e explanação teórica de temas diversos dentro da minha área de conhecimentos.

\section{O membro B respondeu:}

A forma de organização da escola e da universidade na sociedade burguesa é uma forma cartesiana; sendo assim, os currículos são organizados de uma maneira mecânica, partindo do pressuposto de que a cultura e o conhecimento, de maneira geral, são pequenas partes de uma totalidade que podem ser separadas umas das outras. Então, essa organização disciplinar da escola e da universidade, a partir de pressupostos mecânicos, em última instância, está nos moldes cartesianos do início da Idade Moderna. Os grupos de estudo e pesquisa rompem com essa tradição, ou seja, permitem uma possibilidade de ruptura disciplinar, em função da liberdade pressuposta, liberdade no sentido de estudar temas e desenvolver áreas de pesquisa que não estão prerrecortadas pela organização curricular da universidade. Isso é muito importante para o processo de formação. Os grupos de pesquisa permitem uma grande margem de autonomia e liberdade no desenvolvimento da educação continuada e, com isso, no processo de formação como um todo dos sujeitos de pesquisa, dos alunos, enfim, dos atores sociais da universidade em geral. O nosso grupo é um exemplo disso, pois os temas atualmente estudados admitem uma margem grande de liberdade, principalmente em relação aos parâmetros materialistas que dominam a área de ciências humanas.

\section{O membro C respondeu:}

1 - [...] é de grande relevância na minha formação continuada, especialmente por manter-me conectado aos avanços científicos e possibilitar um local de constante reflexão e questionamento. Essa dinâmica colabora com meu posicionamento frente às questões mais urgentes de nosso tempo e com as escolhas ético-políticas, na medida em que coloca o Outro e a justiça como condições da pesquisa. Certamente, essa formação continuada se reflete em minha atuação profissional em sala de aula (quer virtual, quer presencial), nos projetos de extensão, que coordeno, e na pesquisa acadêmica propriamente dita.

2 - A investigação teórica, associada à experiência pedagógica e às preocupações acerca do Outro e da Justiça, jamais é neutra, pois, no fim, se trata da ação de um sujeito historicamente localizado e em determinada situação. Desse modo, os efeitos das atividades do grupo não se restringem à academia, mas a ultrapassam, na medida em que tecem uma comunidade de afetos, que, por sua vez, irmanam o grupo a outros grupos, cujo marco teórico é uma expressão, não seu limite. Sintetizando, pensamento e vida andam de mãos dadas, não se separam.

\section{O membro D respondeu:}

1 - O grupo de estudos mantém vivas a prática do estudo e a da reflexão coletiva. Isto é fundamental não só para a formação profissional, mas para a própria formação humana. Além disso, a temática mantém-me atualizada sobre as problemáticas que estão em foco em minha área de interesse de pesquisa. Outro elemento importante é que no grupo circulam informações sobre novas publicações, materiais de estudo disponíveis na Internet, eventos sobre vários assuntos relacionados à grande área de conhecimento, além do contato com pessoas que podem dialogar comigo, ampliando meu entendimento acerca de assuntos diversos.

2 - O grupo representa um momento só meu. Um momento em que eu me desconecto como profissional que deve formar o outro e me coloco como aprendiz, como ouvinte, como ser humano em formação. No grupo, eu me sinto uma criança ávida de novos saberes. Há sempre 
novos saberes e/ou novos olhares sobre velhos saberes, o que muito me enriquece. No grupo, mantenho contato com meus professores, e cada nova pessoa que entra parece trazer um frescor ao grupo. O grupo é um momento de aprendizagem, e ao mesmo tempo, de descontração, pois se cultivam o respeito e a liberdade de expressão. Eu me sinto muito feliz a cada grupo que se encerra, renovada em meus pensamentos.

\subsubsection{Os encontros remotos do Gepees}

Os encontros remotos, quinzenais, foram produtivos em 2020, principalmente em discussões (leituras de textos) e produção de material, como também pela participação em eventos que tiveram por temática a decolonialidade e a interculturalidade, em especial a partir do pensamento latino-americano. As entrevistas expostas no item 2.1, em comunhão com as atividades do Gepees, resultaram em livro, material didático, artigos científicos e capítulos de livros, além das pesquisas científicas. Iniciação, mestrado, doutorado e pós-doutorado demonstram a coesão, organicamente teórica e prática, indispensável a um grupo que busca investigar e compreender a sociedade contemporânea e suas interfaces com a educação.

\section{$3 \mathrm{O}$ elo - estudo e pesquisa, aulas remotas e a partilha}

Nesse âmbito de estudo e pesquisa, em que a sala de aula, independente de ser virtual ou presencial, é mais que espaço para ousar na construção-desconstrução-construção de conceitos, nos atrevemos a interpretá-la como um possível princípio do decolonial - por representar não apenas "uma opção de conhecimento, uma opção acadêmica, um domínio de estudo, mas uma opção de vida, de pensar e de fazer" (Mignolo, 2014, p. 44) e, assim, desafiar as metodologias, endossando o que escreve Santos:

Hoje não se trata tanto de sobreviver como de saber viver. Para isso é necessária uma outra forma de conhecimento, um conhecimento compreensivo e íntimo que não nos separe e antes nos una pessoalmente ao que estudamos. A incerteza do conhecimento, que a ciência moderna sempre viu como limitação técnica destinada a sucessivas superações, transforma-se na chave do entendimento de um mundo que, mais do que controlado, tem de ser contemplado (Santos, 2008, p. 85-86).

Este artigo é para inquietar, a priori, nossos métodos, nossas escolhas de leitura e, principalmente, o que se propõe ao nosso alunado: "O poético, ou seja, a poiesis, ou seja a criação, poderia reatualizar o horizonte simbólico do indígena e, por conseguinte, reintegrar a totalidade de seu existir” (Kusch, 1976, p. 112). Nesse diálogo poético e intercultural, nossa educação pode possibilitar o encontro com o outro num momento em que ressignificar o ensino não deve ser só por conta da pandemia que estamos enfrentando, mas para rever nossa própria ação com o passado, para enfrentar a crise do presente e repensar o futuro, articulado com novos elos, elos até aqui esquecidos e deixados à margem. 


\section{Considerações finais}

Os conteúdos integraram a elaboração e a representação narrativa da continuidade temporal passado, presente e futuro. O intuito foi fornecer subsídios para consolidar uma educação multirracial, e nela intervir. A estratégia utilizou, além dos conteúdos programáticos, aportes teóricos e linguagens culturais (livros literários e filmes). O processo foi direcionado a suprir determinadas carências apresentadas durante a investigação. A pesquisa-ação, num tratamento qualitativo dos dados: a) analisou as narrativas apresentadas em dissertações; b) investigou a atribuição dos significados do termo indígena.

Cabe ressaltar, neste contexto, que a visão e o processo da temática relacionada aos povos indígenas alcançaram resultados pertinentes com acadêmicos - durante as aulas remotas - desde a desmitificação das lacunas e, sobretudo, da desconstrução de conceitos e pré-conceitos apresentados nas dissertações dos alunos sobre os povos indígenas. É de grande importância a partilha no Grupo de Estudo e Pesquisa em Educação, Ética e Sociedade (Gepees), que possibilitou também esta ininterrupta construção-desconstrução-construção em nossa ação, enquanto pesquisadores no âmbito da educação. Conclui-se que a utilização das linguagens culturais contribuiu para o processo da formação da consciência histórica em conjunto com o conteúdo programático e o contato significativo com outros pesquisadores do Gepees.

\section{Agradecimentos}

Ao Programa de Pós-Graduação em Educação da Faculdade de Filosofia e Ciências da Universidade Estadual Paulista - Unesp -Marília/SP. Ao Grupo de Estudo e Pesquisa em Educação, Ética e Sociedade - GEPEES - Faculdade de Filosofia e Ciências da Universidade do Estado de São Paulo - Unesp Marília/SP. Ao UniSALESIANO - Centro Universitário Católico Salesiano Auxilium -, Araçatuba/SP.

\section{Referências}

Adichie, C. N. (2019). O perigo de uma história única. São Paulo: Companhia das Letras.

Alencar, J. (2018). Iracema. Rio de Janeiro: BestBolso.

Amorim, C.; Paladino, M. (2012). Cultura e literatura africana e indigena. Curitiba: IESDE Brasil S.A.

Andrade, M. (2016). Macunaíma. São Paulo: Martin Claret.

Bauman, Z. (1995). A vida fragmentada: ensaios sobre a moral pós-moderna. Lisboa: Relógio d’ Água.

Bergamaschi, M. A.; Zen, M. I. H.; Xavier, M. L. M. F. (Orgs.). (2012). Povos Indígenas e Educação. Porto Alegre: Meditação.

Brasil. Lei $n^{0}$. 11.645, de 10 março de 2008. Altera a Lei no 9.394, de 20 de dezembro de 1996, modificada pela Lei no 10.639, de 9 de janeiro de 2003, que estabelece as diretrizes e bases da educação nacional, para incluir no currículo oficial da rede de ensino a obrigatoriedade da temática "História e Cultura AfroBrasileira e Indígena”. Brasília, 2008. Recuperado de http://www.planalto.gov.br/ccivil_03/_ato20072010/2008/lei/111645.htm. 
Carvalho, A. B. (2016). A relação professor e aluno: paixão, ética e amizade na sala de aula. Curitiba: Appris.

Dussel, E. (2012). Ética da Libertação: na idade da globalização e da exclusão. Petrópolis: Vozes.

Dussel, E. (1993).1492 - O encobrimento do outro: a origem do "mito da Modernidade". In: Conferências de Frankfurt. Trad. de Jaime A. Clasen. Petrópolis, RJ: Vozes.

Freire, P. (1980). Conscientização: teoria e prática da libertação - uma introdução ao pensamento de Paulo Freire. São Paulo: Cortez \& Moraes.

Freire, P. (1981a). Educação e mudança. Rio Janeiro: Paz e Terra.

Freire, P. (1981b). Ação cultural para a liberdade e outros escritos. Rio de Janeiro: Paz e Terra.

Freire, P. (1997). Política e educação. São Paulo: Cortez.

Freire, P. (2002). Educação como prática da liberdade. Rio de Janeiro: Paz e Terra.

Freire, P. (2003). Educação e Atualidade Brasileira. São Paulo: Cortez; Instituto Paulo

Freire.

Freire, P. 2016. Conscientização. São Paulo: Cortez.

Hall, S. (2015). A identidade cultural na pós-modernidade. Rio de Janeiro: DP\&A.

Jecupé, K. W. (2020). A terra dos mil povos: história indígena do Brasil contada por um índio São Paulo: Peirópolis.

Kusch, Rodolfo. Geocultura del hombre americano. Buenos Aires: Fernando Garcia Cambeiro, 1976.

Medeiros, J. S. Povos indígenas e a Lei $\mathrm{n}^{\circ}$ 11.645: (in) visibilidades no ensino da história do Brasil. In: Bergamaschi, M. A.; Zen, M. I. H.; Xavier, M. L. M. F. (Orgs.). 2012. Povos Indígenas e Educação. Porto Alegre: Meditação.

Mignolo, W. D. (2008). La opción de-colonial: desprendimiento y apertura. Un manifiesto y un caso. Tabula Rasa: Bogotá - Colombia, n. 8: 243-281, enero-junio/2008. Recuperado de http://www.revistatabularasa.org/numero-8/mignolo1.pdf.

Munduruku, D. (2012). O caráter educativo do movimento indígena brasileiro (1970-1990). Coleção Educação em foco. São Paulo: Paulinas.

Quijano, A. Colonialidade do poder, eurocentrismo e América Latina. In: Lander, E. (Org.). 2005. p. 118142. A colonialidade do saber: eurocentrismo e ciências sociais. Perspectivas latino-americanas. Buenos Aires, Colección Sur Sur.

Quijano, A. Os Fantasmas da América Latina. Tradução de Olga Cafalcchio. In: NOVAES, A. (Org.). (2006). Oito visões da América Latina. São Paulo: Editora Senac, 
Ribeiro, Darcy (s. d.). Maíra. Editora Civilização Brasileira S.A.: São Paulo.

Rüsen, J. (2010a). História viva - Teoria da história III: forma e funções do conhecimento histórico. Trad. Estevão de Rezende Martins. Brasília: UnB.

Rüsen, J. (2010b). Raz̃ão histórica - Teoria da história: os fundamentos da ciência histórica. Tradução: Estevão C. de Rezende Martins. Brasília: Editora Universidade de Brasília.

Rüsen, J. (2014). Cultura faz sentido: orientações entre o ontem e o amanhã. Tradução: Nélio Schneider. Petrópolis: Vozes.

Rüsen, J. (2015). Teoria da história: uma teoria da história como ciência. Tradução: Estevão C. de Rezende Martins. Curitiba: Editora UFPR.

Santos, B. S. S. (2008). Um discurso sobre as ciências. São Paulo: Cortez.

Scliar, M. (2009). A majestade do Xingu. São Paulo: Companhia das Letras.

Souza, José Otávio Catafesto de (2012). Reconhecimento oficial da autonomia e da sabedoria dos agentes originários e reorientação do projeto (Inter) Nacional Brasileiro. In: Bergamaschi, M. A.; Zen, M. I. H.; Xavier, M. L. M. F. (Orgs.). Povos Indígenas e Educação. Porto Alegre: Meditação.

\section{Sobre os Autores}

\section{SUELI DO NASCIMENTO}

(iD) ORCID: https://orcid.org/0000-0002-7043-3480

Doutoranda em Educação pela Faculdade de Filosofia e Ciências da Universidade Estadual Paulista Unesp - Marilia/SP. Mestre em Educação, graduada em Pedagogia, Letras e História; professora no Centro Universitário Católico Salesiano Auxilium - Araçatuba/SP; integrante do Grupo de Estudo e Pesquisa em Educação, Ética e Sociedade - GEPEES - Faculdade de Filosofia e Ciências da Universidade Estadual Paulista - Unesp - Marília/SP.

sueli.unisalesiano@gmail.com

\section{ALONSO BEZERRA DE CARVALHO}

(iD) ORCID: https://orcid.org/0000-0001-5106-2517

Doutor e mestre em Educação; pós-doutor em Ciências da Educação; graduado em Filosofia e em Ciências Sociais; professor adjunto do Departamento de Didática e do Programa de Pós-Graduação em Educação da Faculdade de Filosofia e Ciências da Universidade Estadual Paulista - Unesp -Marília/SP; líder do Grupo de Estudo e Pesquisa em Educação, Ética e Sociedade - GEPEES - Faculdade de Filosofia e Ciências da Universidade do Estado de São Paulo - Unesp - Marilia/SP.

alonso.carvalho@unesp.br

Enviado: 18 dez. 2020.

Aprovado: 18 mar. 2021. 